\title{
Updated Evaluation of Dupilumab in the Treatment of Asthma: Patient Selection and Reported Outcomes
}

\author{
This article was published in the following Dove Press journal: \\ Therapeutics and Clinical Risk Management
}

\author{
G Daniel Brooks \\ The Asthma and Allergy Center, Bellevue, \\ NE, USA
}

\begin{abstract}
Uncontrolled asthma continues to be a problem for many patients with moderateto-severe allergic asthma. Dupilumab, which blocks the receptors for interleukin-4 and interleukin-13, has been effective in reducing asthma exacerbations, improving forced expiratory volume in one second $\left(\mathrm{FEV}_{1}\right)$, and reducing oral corticosteroid use. When selecting patients for dupilumab, it is important to consider entry criteria for the original studies, subgroups that have responded best, and the presence of comorbid diseases that may also respond to dupilumab. Factors that were considered when selecting patients likely to respond to dupilumab in asthma studies include: failure of moderate or high dose inhaled steroids in combination with an additional controller medication, baseline $\mathrm{FEV}_{1}$ reversibility of $12 \%$ or greater, and Asthma Control Questionnaire $>1.5$. The baseline characteristics that predicted a better response to dupilumab included blood eosinophils $>150$ cells $/ \mathrm{mm}^{3}$ and fractional exhaled nitric oxide $>25$ parts per billion. Comorbidities that may also respond to treatment with dupilumab include atopic dermatitis, chronic rhinosinusitis, and allergic rhinitis. A combination of these factors should be considered when selecting the patients most likely to benefit from dupilumab.
\end{abstract}

Keywords: allergic asthma, dupilumab, eosinophils, nitric oxide, comorbidity

\section{Allergic Inflammation in Asthma}

A significant proportion of patients with moderate-to-severe asthma continue to have poor control of asthma symptoms and develop exacerbations despite treatment with combination controller medications, including high doses of inhaled steroids. ${ }^{1}$ About half of patients with severe asthma will have allergic airway inflammation that is refractory to treatment with inhaled steroids. ${ }^{2}$

Allergic inflammation in asthma is characterized by cytokines produced by T helper, type 2 cells (Th2 cells). ${ }^{3}$ Th2 cells secrete interleukin (IL)-4, IL-5, and IL-13. IL-4 promotes the differentiation of additional Th2 cells. The Th2 cells migrate to the airway and secrete more IL-4, IL-5 and IL-13. IL-5 promotes eosinophil maturation, activation and survival. IL-13 in the airway promotes immunoglobulin E (IgE) synthesis, mucus hyper-secretion, goblet cell hyperplasia, fibrosis and airway hyper-responsiveness. See Figure 1.

The receptors for IL-4 and IL-13 have one protein in common, the IL-4 receptor alpha subunit. Dupilumab is a fully human monoclonal antibody directed against the IL-4 receptor alpha subunit. By targeting the common subunit, it blocks the actions of both IL-4 and IL-13. Dupilumab has been approved by the United States Food and Drug Administration (FDA) for use in asthma, atopic dermatitis, and chronic rhinosinusitis with nasal polyposis. This
Correspondence: G Daniel Brooks The Asthma and Allergy Center, 3503 Samson Way, Suite 108, Bellevue, NE 68123 , USA

$\mathrm{Tel}+\mathrm{I}-402-592-2055$

Fax + I-402-592-2419

Email gdbrooks@asthmaandallergycenter. com 


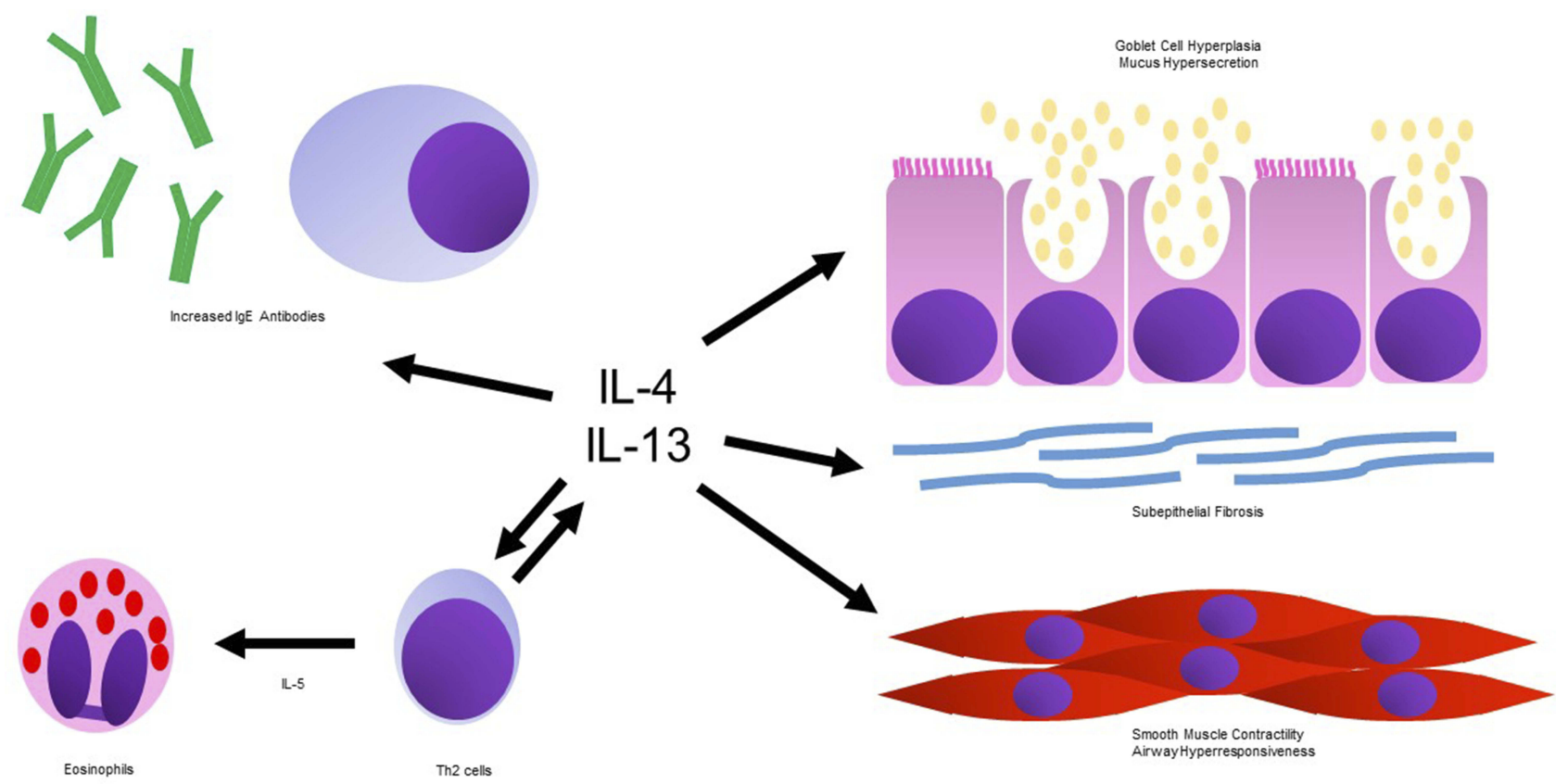

Figure I Asthma related actions of interleukin-4 and interleukin- 13.

Abbreviations: IL-4, interleukin-4; IL-13, interleukin- I3; IL-5, interleukin-5; IgE, immunoglobulin E; Th2, T helper 2.

review examines the characteristics of patients that predict better outcomes in addition to the consideration of comorbid conditions that help determine patient selection for dupilumab. ${ }^{4}$

Alternative biologic therapies, which target mediators of Th2 inflammation, have also been FDA approved for the treatment of severe asthma. Omalizumab (anti-IgE), mepolizumab (anti-IL-5), reslizumab (anti-IL-5), and benralizumab (anti-IL-5 receptor) are all safe and effective in patients with severe asthma. There are no studies with a direct comparison of these drugs to dupilumab, so they will not be compared further. The purpose of this review is to provide an in depth summary of factors that would affect patient selection for dupilumab and serve as a single reference for applicable studies.

The FDA approved asthma indications of dupilumab are for "add-on maintenance treatment in patients with moderate-to-severe asthma aged 12 years and older with an eosinophilic phenotype or with oral corticosteroid dependent asthma." The evidence to support these indications includes two Phase 3 studies of uncontrolled moderate-to-severe asthma and one phase 3 study of steroid dependent asthma. ${ }^{5,6}$ One of the considerations when using dupilumab should be the basic characteristics of the asthma for patients who entered these studies. See Table 1.

\section{How Patients Were Selected for Dupilumab Studies \\ Moderate-to-Severe Asthma}

Most of the patients studied on dupilumab had two different measures of poor asthma control despite treatment with moderate or high dose inhaled steroids in combination with an additional controller medication. The trials of dupilumab in moderate-to-severe asthma enrolled patients age 12 and older. In order to qualify for the trial, the patients had to be uncontrolled on a total daily dose of $500 \mu \mathrm{g}$ fluticasone propionate or greater. Patients also had

Table I Inclusion Characteristics of Patients in Dupilumab Studies

\begin{tabular}{|l|l|}
\hline Baseline Characteristics & Considerations \\
\hline $\begin{array}{l}\text { Failing > } 500 \mu \mathrm{g} \text { of } \\
\text { fluticasone propionate }\end{array}$ & $\begin{array}{l}\text { Inclusion criterion for all of the phase } \\
3 \text { asthma trials }\end{array}$ \\
\hline $\begin{array}{l}\text { Failing an additional } \\
\text { controller medication }\end{array}$ & $\begin{array}{l}\text { Inclusion criterion for all of the phase } \\
3 \text { asthma trials }\end{array}$ \\
\hline $\begin{array}{l}\text { I2\% reversibility in FEV } \\
\text { baseline }\end{array}$ & $\begin{array}{l}\text { Inclusion criterion for moderate-to- } \\
\text { severe trials }\end{array}$ \\
\hline $\begin{array}{l}\text { Asthma Control } \\
\text { Questionnaire }>\text { I.5 }\end{array}$ & $\begin{array}{l}\text { Inclusion criterion for moderate-to- } \\
\text { severe trials }\end{array}$ \\
\hline $\begin{array}{l}\text { Oral glucocorticoid } \\
\text { dependent asthma }\end{array}$ & $\begin{array}{l}\text { Inclusion criteria for severe steroid } \\
\text { dependent trial }\end{array}$ \\
\hline
\end{tabular}

Abbreviation: $\mathrm{FEV}_{1}$, forced expiratory volume in one second. 
to be taking up to two additional controller medications (typically a long acting beta-agonist, though other controllers were permitted). Qualifying characteristics of poor control included both baseline $\mathrm{FEV}_{1}$ reversibility of $12 \%$ or more and Asthma Control Questionnaire (ACQ-5) of 1.5 or higher. The subjects also had one exacerbation in the last year defined by hospitalization, emergency room visit, or oral steroid burst of at least three days. The FEV reversibility is a limitation because in clinical practice, a significant number of patients only have $\mathrm{FEV}_{1}$ reversibility when they have asthma triggers or exacerbations. These patients were not represented in the trial.

Within these phase 3 trials, patients were randomly assigned in a $2: 2: 1: 1$ ratio to subcutaneous dupilumab $200 \mathrm{mg}$ (400 mg loading dose), dupilumab $300 \mathrm{mg}$ (600 mg loading dose), or to one of two separate placebo groups that matched volumes to the treatment groups. Treatment was given for 52 weeks. The design included a stepwise examination of primary endpoints. The first primary endpoint specified was the number of severe asthma exacerbations per patient-year during the 52 week time period. The second primary endpoint was the change in absolute $\mathrm{FEV}_{1}$ value from baseline at week 12.

Overall, subjects in the study had a lower rate of asthma exacerbations for both doses studied. The rate of annualized severe exacerbations was 0.46 versus 0.87 for the $200 \mathrm{mg}$ dupilumab group and matching control (47\% lower, $\mathrm{p}<0.001)$. The rate was 0.52 versus 0.97 for the $300 \mathrm{mg}$ dupilumab group and matching control (46\% lower, $\mathrm{p}<0.001)$. The $\mathrm{FEV}_{1}$ also improved 0.14 liters versus placebo for the lower dose $(\mathrm{p}<0.001)$ and 0.13 liters versus placebo for the higher dose $(\mathrm{p}<0.001)$.

\section{Steroid-Dependent Asthma}

There was a single, separate trial to examine the role of dupilumab in steroid-dependent asthma. Patients in this trial were over age 12 and had a one year history of asthma. They needed to have a six month history of regular systemic steroids to be included in the study. The patients were on a range of prednisone doses, from $5 \mathrm{mg}$ to $35 \mathrm{mg}$, or the equivalent. They also had to be taking $>500 \mu \mathrm{g}$ of fluticasone propionate daily (or the equivalent) in combination with up to two other controller medications. A total of 210 study subjects were assigned randomly in a $1: 1$ ratio to either $300 \mathrm{mg}$ dupilumab (600 mg loading dose) or placebo. Oral glucocorticoid dose was reduced every four weeks for 20 weeks with an assessment of adjusted glucocorticoid dose at 24 weeks. The adjusted glucocorticoid dose was the smallest dose that could be achieved without having a severe asthma exacerbation, an increase of 0.5 in the five question Asthma Control Questionnaire, or other outcome that caused glucocorticoids to be increased again.

The patients on dupilumab were more successful at reducing their oral steroid dose than the placebo group. The least square mean reduction in glucocorticoid dose was $70.1 \%$ in the dupilumab group and $41.9 \%$ in the placebo group $(\mathrm{p}<0.001)$. The median dose reduction was $100 \%$ in the dupilumab group and $50 \%$ in the placebo group. Treatment with dupilumab was also associated with fewer severe asthma exacerbations, greater $\mathrm{FEV}_{1}$ improvement, and improved asthma control (ACQ-5) compared to placebo.

\section{Patient Characteristics Favoring Response to Dupilumab}

Specific subgroups were declared prior to the study in moderate-to-severe asthma. Patients were stratified for separate analyses by blood eosinophil count and fraction of exhaled nitric oxide $\left(\mathrm{FE}_{\mathrm{NO}}\right)$. See Table 2. The patients were placed into three groups based on the presence of low blood eosinophil count $\left(<150\right.$ cells $\left./ \mathrm{mm}^{3}\right)$, moderate

Table 2 Baseline Characteristics Favoring Response in Dupilumab Studies

\begin{tabular}{|l|l|l|}
\hline $\begin{array}{l}\text { Baseline } \\
\text { Characteristics }\end{array}$ & Rationale & Other Considerations \\
\hline $\begin{array}{l}\text { Blood eosinophil count } \\
>300 \text { cells } / \mathrm{mm}^{3}\end{array}$ & $\begin{array}{l}\text { Greatest reduction in asthma exacerbations happened in this } \\
\text { cohort }\end{array}$ & $\begin{array}{l}\text { Elevations of eosinophil count above } 3000 \text { cells } / \mathrm{mm}^{3} \text { in } \\
1.2 \% \text { of patients on dupilumab }\end{array}$ \\
\hline $\begin{array}{l}\text { Blood eosinophil count } \\
>150 \text { cells } / \mathrm{mm}^{3}\end{array}$ & $\begin{array}{l}\text { Asthma exacerbations and } \mathrm{FEV} \text {, were not better than } \\
\text { placebo with eosinophils }<150 \text { cells } / \mathrm{mm}^{3}\end{array}$ & \\
\hline $\mathrm{FE}_{\mathrm{NO}}>25 \mathrm{Ppb}$ & $\begin{array}{l}\text { Asthma exacerbations and } \mathrm{FEV} \text {, were not better than } \\
\text { placebo with lower } \mathrm{FE}_{\mathrm{NO}}\end{array}$ & \\
\hline
\end{tabular}

Abbreviations: $\mathrm{FE}_{\mathrm{NO}}$, fractional exhaled nitric oxide; $\mathrm{FEV}_{1}$, forced expiratory volume in one second; ppb, parts per billion. 
eosinophil count (150-300 cells $\left./ \mathrm{mm}^{3}\right)$, or high eosinophil count $\left(>300\right.$ cells $\left./ \mathrm{mm}^{3}\right)$. For both doses of dupilumab, the greatest reduction (66-67\%) in asthma exacerbations was seen in the group with blood eosinophils greater than 300 cells $/ \mathrm{mm}^{3}$. There was still a significant reduction (36-40\%) in the group with $150-300$ cells $/ \mathrm{mm}^{3}$. The group with blood eosinophils $<150$ cells $/ \mathrm{mm}^{3}$ did not have significantly less exacerbations than the control group. The group with blood eosinophils $>300$ cells $/ \mathrm{mm}^{3}$ demonstrated a $0.21-0.22$ liter improvement in $\mathrm{FEV}_{1}$ versus placebo. The lower eosinophil group did not find a statistically significant improvement.

The study of severe, steroid-dependent asthma performed an analysis of the same three blood eosinophil groups. It might be expected that blood eosinophils would be suppressed at baseline by the oral steroids, but elevated baseline blood eosinophils were relatively common within the study. Only 60 subjects had blood eosinophils $<150$ cells $/ \mathrm{mm}^{3}$ compared to 150 subjects with blood eosinophils $>150$ cells $/ \mathrm{mm}^{3}$. Of these patients, 89 subjects had blood eosinophils $>300$ cells $/ \mathrm{mm}^{3}$. The patients with blood eosinophils $>300$ cells $/ \mathrm{mm}^{3}$ experienced a greater reduction in steroids relative to placebo. In contrast to the other study, subjects in this low eosinophil group still demonstrated a significant reduction in oral steroid dose relative to placebo.

In a separate analysis, the subjects were divided into pre-specified groups by $\mathrm{FE}_{\mathrm{NO}}$ measurement. Subjects with elevated baseline $\mathrm{FE}_{\mathrm{NO}}>25$ parts per billion (ppb) had a significant reduction in exacerbations with both doses of medication studied. Subjects with $\mathrm{FE}_{\mathrm{NO}}<25 \mathrm{ppb}$ did not have a statistically significant reduction in asthma exacerbations. ${ }^{7}$ The $\mathrm{FE}_{\mathrm{NO}}$ groups were also analyzed for $\mathrm{FEV}_{1}$ outcomes. The $\mathrm{FE}_{\mathrm{NO}}>25$ ppb group also predicted $\mathrm{FEV}_{1}$ improvement in response to dupilumab.
A subgroup of allergic asthma patients was studied in a post-hoc analysis. Allergic asthma was defined by the presence of total $\mathrm{IgE}>30 \mathrm{IU} / \mathrm{mL}$ and detectable serum $\operatorname{IgE}$ to at least one perennial aeroallergen. The allergens tested included dust mites, Alternaria, Cladosporium, Aspergillus, cat, dog, and cockroach. Using these criteria, 1083 patients were assigned to the allergic asthma group. The allergic asthma group responded to dupilumab 200/300 mg with a significant decrease in severe exacerbations (37\%/46\% respectively). The other asthma group had a similar improvement.

In a different post-hoc analysis of the phase $2 b$ data, subjects were separated into groups by the baseline frequency of asthma exacerbations. ${ }^{8}$ All groups demonstrated a statistically significant reduction in exacerbations. The treatment effect was greater in the patients with a history of the most exacerbations. These patients had more exacerbations in the placebo group.

\section{Comorbid Conditions to Consider}

There are several comorbid diseases that may influence the selection of patients for dupilumab. See Table 3. Atopic dermatitis, chronic rhinosinusitis, and allergic rhinitis may all have symptom improvement with the usage of dupilumab. Meanwhile, concurrent hypereosinophilic syndromes warrant caution.

\section{Atopic Dermatitis}

Patients with comorbid atopic dermatitis may have a significant improvement in their skin symptoms when treated with dupilumab. Before dupilumab was approved for asthma, it was approved for atopic dermatitis. Three trials of dupilumab were performed in patients with moderate-to-severe atopic dermatitis not controlled by topical corticosteroids. $^{4,9,10}$ Subjects received $600 \mathrm{mg}$ dupilumab

Table 3 Using Dupilumab in the Presence of Specific Comorbid Diseases

\begin{tabular}{|l|l|l|}
\hline Comorbid Disease & Rationale & Other Considerations \\
\hline Atopic dermatitis & $\begin{array}{l}35-40 \% \text { of patients had significant improvement } \\
\text { in symptoms of pruritus }\end{array}$ & $\begin{array}{l}\text { Conjunctival or other eye side effects appeared more often } \\
\text { in studies of atopic dermatitis }\end{array}$ \\
\hline $\begin{array}{l}\text { Chronic rhinosinusitis with } \\
\text { nasal polyps }\end{array}$ & $\begin{array}{l}\text { Nasal polyps reduced in size and nasal symptom } \\
\text { scores improved }\end{array}$ & FEV and asthma control improved in these patients \\
\hline Allergic rhinitis & Allergic rhinitis symptoms improved & Studies were from post-hoc analyses \\
\hline $\begin{array}{l}\text { Hypereosinophilic syndrome } \\
\text { Chronic eosinophilic pneumonia } \\
\text { (Caution, consider avoiding) }\end{array}$ & Eosinophils were increased during treatment & $\begin{array}{l}\text { Severe adverse event of worsening chronic eosinophilic } \\
\text { pneumonia reported }\end{array}$ \\
\hline
\end{tabular}

Abbreviation: $\mathrm{FEV}_{1}$, forced expiratory volume in one second. 
initial dose followed by $300 \mathrm{mg}$ of dupilumab every two weeks or placebo. Reduction in itch score of four points was defined as a clinically significant response. In the first two, 16 week, studies $36 \%$ and $41 \%$ achieved this reduction in itch with dupilumab, compared to $9.5 \%$ and $12.3 \%$ with placebo. In the third study, $36 \%$ of people maintained their response at 52 weeks. This was a mixture of people who responded at 16 weeks and people who responded late. Of note, individuals in the atopic dermatitis trials were more likely to have conjunctivitis, blepharitis, keratitis, and eye pruritus on dupilumab than placebo. This side effect was not statistically significant in studies of asthma, so it appears to be more likely to happen in patients with atopic dermatitis.

\section{Chronic Rhinosinusitis with Nasal Polyposis}

Bachert et al first reported that chronic sinusitis and nasal polyps responded to dupilumab in a study of 60 patients. ${ }^{11}$ Patients were randomized to either dupilumab $300 \mathrm{mg}$ (600 mg loading dose) or placebo. The primary endpoint was endoscopic nasal polyp score at 16 weeks, which was significantly lower in the dupilumab treatment group $(p<0.001)$. Significant improvements in the computed tomography scan of the sinus, the SinoNasal Outcome Test (SNOT-22), and sense of smell were also reported as secondary endpoints. A subsequent subgroup analysis was performed on 35 subjects with asthma. ${ }^{12}$ Within this group, dupilumab was associated with improved asthma control and quality of life.

The rationale for prescribing dupilumab to patients with nasal polyps was strengthened in June of 2019, when the FDA gave approval for the use of dupilumab in patients who have chronic rhinosinusitis with nasal polyposis (CRSwNP). ${ }^{4}$ The basis of this approval was the outcome of two randomized, double-blind, placebo-controlled studies. The studies included subjects with CRSwNP who were refractory or intolerant of surgery or nasal steroids in the previous two years. The first study had 276 subjects who were randomized to receive either $300 \mathrm{mg}$ of dupilumab or placebo every other week for 24 weeks. ${ }^{13,14}$ Dupilumab treatment resulted in improved endoscopic nasal polyp scores and nasal congestion symptoms scores. It was also associated with significantly less need for systemic steroids or surgery. In patients with comorbid asthma, it was associated with improved $\mathrm{FEV}_{1}$ and asthma control.

The second study had 448 subjects randomized to $300 \mathrm{mg}$ of dupilumab every other week for 52 weeks, $300 \mathrm{mg}$ of dupilumab every other week for 24 weeks, followed by every four weeks until week 52, or placebo. ${ }^{13,15}$ The nasal polyp endoscopic score, nasal congestion symptom score, and need for systemic steroids or polyp surgery were all reduced. Patients with asthma again had improved $\mathrm{FEV}_{1}$ and asthma control.

\section{Chronic Rhinosinusitis}

The phase 3 moderate-severe asthma study data was later analyzed to examine whether patients with self-reported chronic rhinosinusitis symptoms were more likely to have an improvement in their asthma outcomes. ${ }^{16}$ A significant limitation of the study was that data on nasal polyposis had not been collected. Patients with chronic rhinosinusitis generally had higher blood eosinophils and $\mathrm{FE}_{\mathrm{NO}}$ at baseline but lower rates of allergic sensitization. During the study, chronic rhinosinusitis patients assigned to placebo had a greater number of severe asthma exacerbations than the placebo treated patients without chronic rhinosinusitis. Both groups had a statistically significant decrease in severe exacerbations. The decrease attributed to dupilumab was greater in the chronic rhinosinusitis group $(61 \%)$ than in the other group (40\%).

\section{Allergic Rhinitis}

Post hoc analyses of patients have found that allergic rhinitis symptoms improved while on dupilumab and that asthma improved in the subset of patients with allergic rhinitis. Weinstein analyzed the effect of dupilumab on nasal symptom scores in a post-hoc analysis of a phase $2 \mathrm{~b}$ trial. ${ }^{17}$ Perennial allergic rhinitis was determined by the presence of detectable serum IgE to Aspergillus, cat, dog, dust mite, German cockroach or Oriental cockroach. Patients with nasal polyps were excluded. Nasal symptoms were measured using the Sino-Nasal Outcome Test (SNOT-22) after 24 weeks. Blinded, randomized 1:1:1:1 assignment of groups was to dupilumab 200 mg every 2 weeks, dupilumab 300 mg every two weeks, dupilumab $300 \mathrm{mg}$ every 4 weeks, or placebo. The allergic rhinitis group treated with $300 \mathrm{mg}$ dupilumab every two weeks had a significant improvement in the SNOT-22 score compared to the placebo group. This included statistically significant improvements in nasal congestion, rhinorrhea, sneezing and postnasal drainage. The $200 \mathrm{mg}$ dupilumab group also had better scores than placebo but this was not statistically significant. Study subjects without allergic rhinitis did not have significant response in SNOT-22. Within this study, FEV1 improved in patients with allergic rhinitis treated with $300 \mathrm{mg}$ dupilumab and patients without allergic rhinitis treated with $200 \mathrm{mg}$ 
dupilumab compared to placebo. Severe asthma exacerbations were decreased significantly in patients with allergic rhinitis treated with $300 \mathrm{mg}$ dupilumab. In patients without perennial allergic rhinitis, exacerbation were decreased significantly with both doses.

\section{Caution with Hypereosinophilic Conditions}

Although high blood eosinophil count predicted the asthma response to dupilumab relative to placebo, it is notable that dupilumab was associated with increases of blood eosinophil count in a subset of patients. In the moderate-to-severe asthma studies, blood eosinophil count $>3000$ cells $/ \mathrm{mm}^{3}$ was reported in $1.2 \%$ of the treatment group versus $0.3 \%$ of the placebo group. One subject had a serious adverse event of worsening hypereosinophilia and seven patients were discontinued from the trial because of eosinophil elevations.

Chronic eosinophilic pneumonia was diagnosed in one patient who was taking dupilumab $300 \mathrm{mg}$ every two weeks in the moderate-severe asthma trial. ${ }^{18}$ At the third injection, he was asymptomatic but blood eosinophils were elevated $\left(1840\right.$ cells $\left./ \mathrm{mm}^{3}\right)$. Before the tenth injection, he presented with fever, blood eosinophilia (2080 cells $/ \mathrm{mm}^{3}$ ), and bilateral pulmonary opacities. After failure of antibiotics, bronchial biopsy and bronchoalveolar lavage were consistent with chronic eosinophilic pneumonia. After six months of oral corticosteroid taper, imaging confirmed resolution of opacities and blood eosinophils were 40 cells $/ \mathrm{mm}^{3}$.

The severe, steroid-dependent asthma study found that $13 \%$ of patients in the dupilumab group had a blood eosinophil count $>3000$ cells $/ \mathrm{mm}^{3}$. In this study, the increases were transient, and the levels returned to baseline by the end of the treatment period. Given these reports, caution should be taken when considering dupilumab on patients with a history of comorbid hypereosinophilic syndrome or chronic eosinophilic pneumonia.

\section{Other Cautions}

Patients should not stop oral or inhaled steroids immediately upon starting dupilumab. The package insert recommends gradual reduction of steroid dose. In the steroid reduction study, patients were treated with dupilumab for four weeks prior to the initiation of steroid reduction and doses were reduced every four weeks if the patient was well controlled. The exact reduction schedule in the study involved a complex table and had subtle differences for different starting doses. However, a representative taper would be prednisone $30 \mathrm{mg}, 20 \mathrm{mg}, 10 \mathrm{mg}, 5 \mathrm{mg}, 2.5 \mathrm{mg}$, and then stop. Most patients could be started in the middle of this taper, even though it varies slightly from the studied protocol. It is important to educate patients who are tapering steroids regarding symptoms of poor asthma control and the need to contact their physician.

Because of the role of Th2 immunity in helminth parasitic defense, any helminth infection should be treated before the initiation of dupilumab. If a patient does contract a helminth while on dupilumab, and fails to respond to treatment, dupilumab should be stopped until the infection resolves.

Urticaria, rash, erythema nodosum, serum sickness and anaphylaxis have occurred after dupilumab administration. These are contraindications to further use.

\section{Conclusions}

A significant proportion of patients with asthma are not controlled with inhaled steroids. The IL-4 receptor alpha blocker, dupilumab, is efficacious in patients with uncontrolled moderate-to-severe asthma. Patients were selected into the original studies based on $\mathrm{FEV}_{1}$ reversibility at baseline and an asthma control questionnaire that indicated poor control. Subsequent analysis demonstrated that important predictors of response to dupilumab include blood eosinophil count greater than 150 cells $/ \mathrm{mm}^{3}$ and $\mathrm{FE}_{\mathrm{NO}}$ greater than $25 \mathrm{ppb}$. Another factor favoring the choice of the dupilumab is the presence of responsive comorbid diseases, including atopic dermatitis, chronic rhinosinusitis with nasal polyposis and allergic rhinitis. Dupilumab is an effective asthma medication for well selected patients not responding to inhaled steroids.

\section{Disclosure}

The Asthma and Allergy Center, employer of Dr. Brooks, has received payment for the conduct of multiple clinical trials from Sanofi, AstraZeneca, GlaxoSmithKline, Novartis, and Teva. The author reports no other conflicts of interest in this work.

\section{References}

1. Hermosa JL, Sanchez CB, Rubio MC, Minguez MM, Walther JL. Factors associated with the control of severe asthma. J Asthma. 2010;47(2):124-130. doi:10.3109/02770900903518835

2. Peters MC, Kerr S, Dunican EM, et al. Refractory airway type 2 inflammation in a large subgroup of asthmatic patients treated with inhaled corticosteroids. J Allergy Clin Immunol. 2019;143(1):104. doi:10.1016/j.jaci.2017.12.1009

3. Robinson D, Humbert M, Buhl R. Revisiting type 2-high and type 2-low airway inflammation in asthma: current knowledge and therapeutic implications. Clin Exp Allergy. 2017;47(2):161-175. doi:10.11 11/cea. 12880

4. Dupixent [package insert]. Tarrytown, NY: Regeneron Pharmaceuticals; 2019. 
5. Castro M, Corren J, Pavord ID, et al. Dupilumab efficacy and safety in moderate-to-severe uncontrolled asthma. $N$ Engl J Med. 2018;378 (26):2486-2496. doi:10.1056/NEJMoa1804092

6. Rabe KF, Nair P, Brusselle G, et al. Efficacy and safety of dupilumab in glucocorticoid-dependent severe asthma. $N$ Engl J Med. 2018;378 (26):2475-2485. doi:10.1056/NEJMoa1804093

7. Corren J, Castro M, O'Riordan T, et al. Dupilumab efficacy in patients with uncontrolled moderate-to-severe allergic asthma. J Allergy Clin Immunol. 2020;8(2):516-526. doi:10.1016/j.jaip.2019.08.050

8. Corren J, Castro M, Ford LB, et al. Dupilumab improves asthma outcomes irrespective of frequency of previous asthma exacerbation history. Ann Allergy Asthma Immunol. 2019;123(2):222-224. doi:10.1016/j. anai.2019.04.028

9. Simpson EL, Bieber T, Guttman-Yassky E, et al. Two phase 3 trials of dupilumab versus placebo in atopic dermatitis. $N$ Engl $\mathrm{J} \mathrm{Med}$. 2016;375(24):2335-2348. doi:10.1056/NEJMoa1610020

10. Blauvelt A, de Bruin-weller M, Gooderham M, et al. Long-term management of moderate-to-severe atopic dermatitis with dupilumab and concomitant topical corticosteroids (LIBERTY AD CHRONOS): a 1-year randomized, double-blinded, placebo-controlled, phase 3 trial. Lancet. 2017;389(10086):2287-2303. doi:10.1016/S0140-67 36(17)31191-1

11. Bachert C, Mannent L, Naclerio RM, et al. Effect of subcutaneous dupilumab on nasal polyp burden in patients with chronic sinusitis and nasal polyposis. JAMA. 2016;315(5):469-479. doi:10.1001/ jama.2015.19330

12. Bachert C, Hellings PW, Mullol J, et al. Dupilumab improves patient-reported outcomes in patients with chronic rhinosinusitis with nasal polyps and comorbid asthma. J Allergy Clin Immunol. 2019;7(7):2447-2449. doi:10.1016/j.jaip.2019.03.023
13. Bachert C, Jan JK, Desrosiers M, et al. Efficacy and safety of dupilumab in patients with severe chronic rhinosinusitis with nasal polyps (LIBERTY NP SINUS-24 and LIBERTY NP SINUS-52): results from two multicenter, randomized, double-blind, placebo-controlled, parallel-group phase 3 trials. Lancet. 2019;394(10209):1638-1650. doi:10.1016/S0140-6736(19)31881-1

14. Han JK, Bachert C, Desrosiers M, et al. Efficacy and safety of dupilumab in patients with chronic rhinosinusitis with nasal polyps: results from the randomized phase 3 Sinus-24 study [abstract]. J Allergy Clin Immunol. 2019;143(2):AB422. doi:10.1016/j.jaci.2018.12.948

15. Bachert C, Desrosiers M, Mullol J, et al. A randomized phase 3 study, Sinus-52, evaluating the efficacy and safety of dupilumab in patients with severe chronic rhinosinusitis with nasal polyps [abstract]. J Allergy Clin Immunol. 2019;143(2):AB433. doi:10.1016/j.jaci.2018.12.980

16. Maspero JF, Katelaris CH, Busse WW, et al. Dupilumab efficacy in uncontrolled moderate-to-severe asthma with self-reported chronic rhinosinusitis. J Allergy Clin Immunol. 2020;8(2):527-539. doi:10.1016/ j.jaip.2019.07.016

17. Weinstein SF, Katial R, Jayawardena S, et al. Efficacy and safety of dupilumab in perennial allergic rhinitis and comorbid asthma. J Allergy Clin Immunol. 2018;142(1):171-177. doi:10.1016/j.jaci.2017.11.051

18. Menzella F, Montari G, Patricelli G, et al. A case of chronic eosinophilic pneumonia in a patient treated with dupilumab. Ther Clin Risk Manag. 2019;15:869-875. doi:10.2147/TCRM.S207402
Therapeutics and Clinical Risk Management

\section{Publish your work in this journal}

Therapeutics and Clinical Risk Management is an international, peerreviewed journal of clinical therapeutics and risk management, focusing on concise rapid reporting of clinical studies in all therapeutic areas, outcomes, safety, and programs for the effective, safe, and sustained use of medicines. This journal is indexed on PubMed Central, CAS,

\section{Dovepress}

EMBase, Scopus and the Elsevier Bibliographic databases. The manuscript management system is completely online and includes a very quick and fair peer-review system, which is all easy to use. Visit http://www.dovepress.com/testimonials.php to read real quotes from published authors. 